\title{
EL ABASTECIMIENTO DE CARNE EN LA CIUDAD DE ALICANTE. CRISIS ACTUAL DEL MATADERO PÚBLICO
}

\author{
José Antonio Segrelles Serrano
}

\begin{abstract}
RESUMEN
En las últimas décadas se ha asistido a profundas mutaciones económicas y sociales que van desde el aumento demográfico hasta el incremento de los niveles de renta. Esto supone violentas sacudidas en el mercado de la carne y en las tradicionales estructuras productivas públicas, que ante el empuje de los mataderos industriales entran en una aguda crisis y se ven cada vez más relegadas a un segundo plano.

El matadero municipal de Alicante no es una excepción. Las transformaciones que ha experimentado el consumo de la población, el cambio en los hábitos de los minoristas, el reducido volumen de sacrificios, la existencia de una oferta poco maleable, la ausencia de una gestión dinámica y profesionalizada, la falta de rentabilidad, e incluso la presencia de una mano de obra infrautilizada, sitúan al matadero público frente a un rotundo y concluyente dilema: o la modernización o el cierre.

El Ayuntamiento ha optado por el camino renovador, realizando importantes reformas e inversiones para adecuarse a su nueva vocación comarcal y a las exigencias técnico-sanitarias del Plan General Indicativo de Mataderos. Para ello no basta con el esfuerzo económico y técnico, sino que debe existir un decidido compromiso por modificar la actual gestión pública del matadero municipal.
\end{abstract}

\begin{abstract}
During the last decades there were deep economic variations, ranging from the demographic growth to level increment in the individual income. These originated strong oscilations in the meat market and on its tradicional public productive structures, which start to fall into a marked crisis and a progresive relegation to a second plane, enhanced by the concurrent industrial butchering factories.

The municipal slaughtering house in Alicante was not an exception. The transformations ocurred in the food consumption in the population, changes in retailers habits, reduced amount of slaughterings, existence of a not well adaptable offer, the absence of a dinamic and proffessionalized management, the lack of yield and even, the low level of manpower utilization, lead the municipal slaughtering house to a perempdtory and conclusive dilema: to modernize or to die.
\end{abstract}


The Municipal Government of Alicante has elected the first way, making important reforms and investments in order to be well prepared to the new county dedication and to the technical and sanitary requirements introduced by the General Plan for Slaughtering Houses. But to get all that, it would be insufficient to make only a considerable economic and technical effort. It is necessary a decided committement to change the present public management in the municipal slaughtering house.

La aguda crisis en que se encuentra sumido nuestro sector cárnico ha sido objeto de atención por parte de numerosos estudios, sobre todo por lo que respecta a las estructuras productivas. Los mataderos, fundamentalmente los públicos, constituyen el punto clave de esta situación crítica, detalle ya puesto de relieve de manera constante en los últimos tiempos. Sin embargo, son los años más recientes, en el seno de las Comunidades Europeas, los que dan una nueva dimensión al problema.

Las exigencias europeas, las nuevas y costosas técnicas, el frenético ritmo de la economía, el crecimiento del sector cárnico privado y el cambio en el gusto de los consumidores hacen que los mataderos públicos oteen un horizonte plagado de negras perspectivas y se empiece a vislumbrar el declive definitivo de una actividad que durante casi un siglo ha sido consustancial a la vida del municipio.

Tanto la Administración Central como las Comunidades Autónomas han asumido de forma plena el problema; se lucha desde muchos terrenos: legislativo, técnico, sanitario y económico, para atajar un acelerado proceso de deterioro. Son varias las soluciones que plantean los expertos, desde el cierre categórico hasta la implantación de nuevas fórmulas empresariales. Sin embargo, cada matadero municipal, aun dentro de unas características comunes, goza de unas particularidades que serán decisivas para que su futuro sea uno u otro.

El matadero municipal de Alicante no escapa a estos planteamientos; forma parte de un sector problemático pero a la vez exhibe una serie de matices distintivos que derivan del talante de sus gestores, de los hábitos de consumo de la población y de su adecuación paulatina a lo legislado, aunque a costa de importantes inversiones.

Por ello, con estas notas pretendemos analizar las características y funcionamiento del matadero municipal alicantino, así como dilucidar su futuro a corto plazo y sus garantías de supervivencia.

\section{Aspectos evolutivos del matadero municipal de Alicante}

El matadero municipal de Alicante no siempre ha estado en el mismo emplazamiento; el primero se concretó hacia 1880 al final de la playa del Postiguet, entre las actuales avenidas de Denia y Villajoyosa (vid. fig. 1). Se trataba de un pequeño habitáculo, de unos cien metros cuadrados, conocido con el nombre de "cuadra de corderos", siendo su finalidad la de garantizar a la población el abastecimiento de carne controlada sanitariamente.

Los problemas de conservación de la carne y la deficiencia de los transportes fueron determinantes para exigir a todos los municipios la creación de mataderos; Alicante, ya desde finales del siglo pasado, siempre estuvo dotada de este servicio público. El hecho de ser 
capital provincial y su progresivo crecimiento demográfico contribuyeron a que quedara de forma constante dentro del umbral poblacional que la legislación estimaba como límite para disponer obligatoriamente de matadero.

A lo largo del presente siglo, los municipios más pequeños fueron eximidos de la obligatoriedad de este servicio, debido a los avances de la economía y de la técnica. Así, en 1918 (Reglamento General de Mataderos) se establecía el umbral en 2.000 habitantes; en 1955 (Ley de Bases de Régimen Local) se obligaba a prestar servicio de matadero a todos aquellos municipios mayores de 5.000 habitantes; actualmente, entre 1981 y 1984, se ha

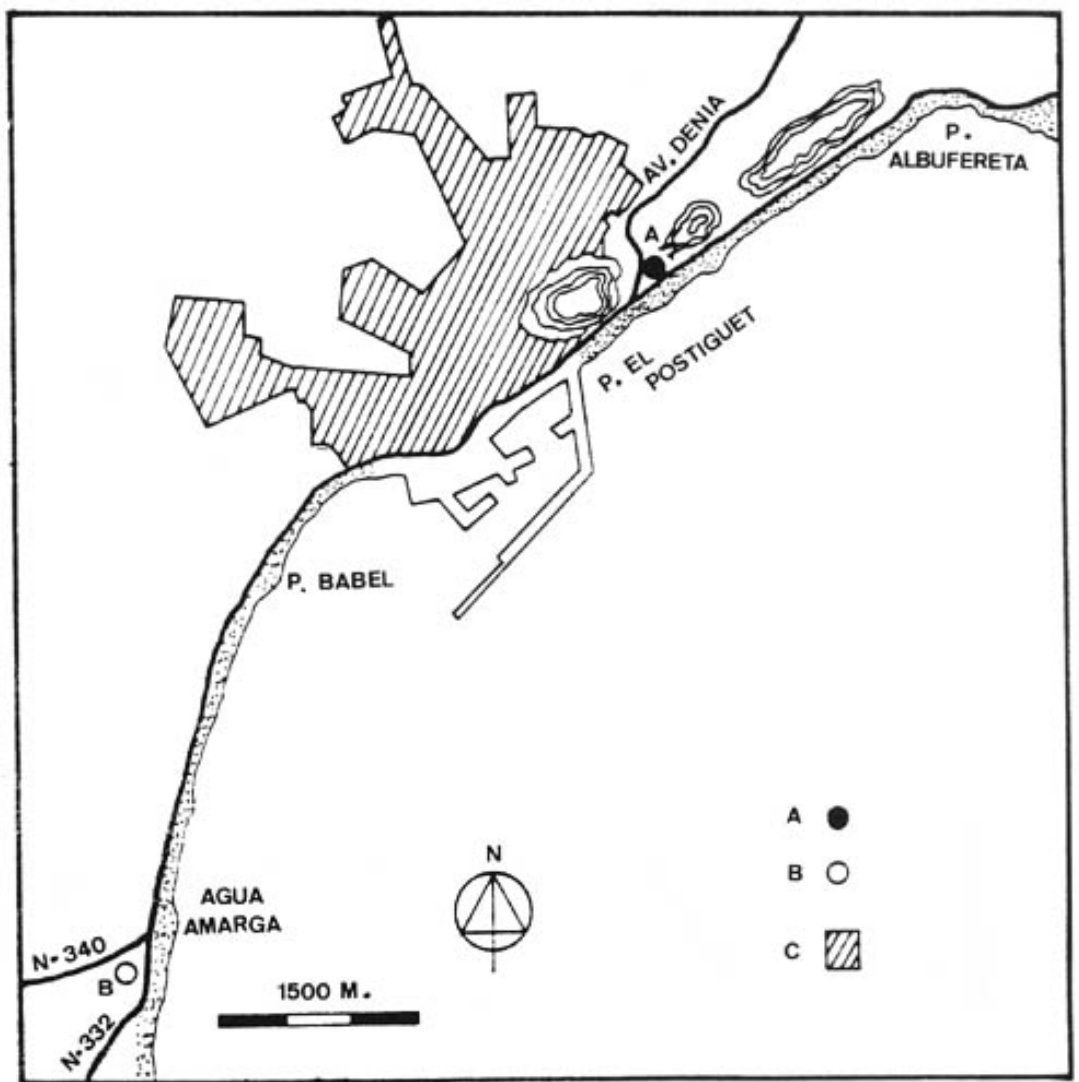

FIGURA 1- Situación del antiguo y nuevo emplazamiento del matadero municipal de Alicante. A, Antiguo emplazamiento; B, Nuevo emplazamiento; C, Edificación en compacto. 
ideado, desarrollado y aprobado el Plan General Indicativo de Mataderos, que ya habla de estructuras de sacrificio de ámbito comarcal.

De esta manera, conforme aumentaba la población y crecía la demanda de carne, el matadero de Alicante se veía obligado a ampliar sus instalaciones, hasta que en 1966 tuvo que cambiar su emplazamiento, pues se había quedado desfasado, casi ruinoso y demasiado céntrico. Además, sus vertidos a una playa con perspectivas futuras lo hacían "competidor" desagradable de una actividad pujante: el turismo.

Aunque el traslado se materializó en 1966, fue en 1960 cuando se adquirieron los nuevos terrenos. Se eligió la zona de Agua Amarga por varias razones (vid. fig. 1). En primer lugar, y ante todo, se tuvo en cuenta el precio del suelo; el propietario, buscando la promoción de la zona, vendió al Ayuntamiento a razón de 1'25 pts./metro cuadrado. En segundo lugar, se consideró una relativa cercanía a la ciudad, pero sin competir por el suelo y otros usos más rentables. En aquellos momentos, el funcionamiento de una actividad nociva (vertidos, olores...), como es el sacrificio de animales, podía llevarse a cabo sin grandes problemas en una zona poco frecuentada por la población, tanto autóctona como alóctona. En tercer lugar, el centro de sacrificio debía estar bien comunicado por carretera con el núcleo urbano al que debía abastecer. El matadero se halla actualmente emplazado en el vértice donde confluyen las carreteras N-340 y N-332. Sin embargo, este factor de localización no tuvo demasiada trascendencia porque si bien la distancia que lo separa de Alicante no es excesiva $(6 \mathrm{Km}$.), esta carretera no gozó de un tráfico fluido hasta 1978, año en que este tramo de la N-332 fue convertido en autovía.

La localización del matadero municipal se muestra hoy problemática. Este área ha experimentado últimamente una verdadera "colonización" por parte de concesionarios de automóviles, almacenes, talleres y distintas empresas públicas y privadas, que comparten su ubicación con una actividad industrial ciertamente molesta e insalubre. Si a esto unimos la dirección que sigue la expansión de la ciudad y la progresiva función residencial y turística de la zona, pronto se encontrará el matadero municipal ante los mismos problemas que tuvo en su antiguo emplazamiento. Hasta ahora el Ayuntamiento no se ha planteado la posibilidad de su traslado, sólo ha luchado por adecuar el matadero a las exigencias técnicas y sanitarias de la CEE, labor que cristalizó en 1987 con el "Proyecto de Reforma y Modernización del Matadero Municipal de Alicante".

Como ya planteamos anteriormente, los mataderos públicos fueron imprescindibles hasta la década de los años sesenta de la presente centuria. No obstante, a partir de este momento se inicia una larga crisis, todavía hoy patente, que no tiene visos de solución. El declive de los mataderos municipales coincide con un importante cambio en el mercado de la carne, transformación que se encuentra mediatizada por los consabidos factores de progresiva concentración urbana, aumentos de renta y población, creciente industrialización, desarrollo de los transportes y mejora de las técnicas de explotación. Todo ello se refleja en una serie de nuevos elementos: la producción ganadera se inclina hacia una explotación intensiva; cobran gran auge especies con elevados índices de conversión, es decir, porcino y pollo en detrimento de vacuno y ovino; aparecen los mataderos privados con gestión empresarial y criterios de rentabilidad; se crean redes de distribución con talante mayorista; los transportes adoptan la tecnología del frío; las carnicerías tradicionales se ven "invadidas" tanto por los minoristas especializados (charcuterías, casquerías, pollerías) como por los comercios de grandes superficies (hipermercados, supermercados) (1). 
Todas estas transformaciones afectan indefectiblemente a los mataderos públicos, que no actúan en un mercado libre, que no persiguen la rentabilidad y que sólo se limitan a ofrecer el servicio de matanza a la población. Se trata, por supuesto, de características enarboladas por el matadero municipal de Alicante que iremos dilucidando a través de su estructura, actividad $\mathrm{y}$ funcionamiento.

\section{Quiénes utilizan los servicios del matadero municipal}

Una figura inherente al matadero público es el popular y conocido "entrador" de ganado o tratante. En esencia, es el intermediario entre el ganadero y el carnicero, y como su propio nombre indica se encarga de "entrar" las reses para el sacrificio. De esta forma, el matadero se desentiende de adquirir las reses y de venderlas después, sólo se dedica al sacrificio de los animales; cuestión que, como veremos más adelante, influye muchísimo en su situación crítica actual.

Con estas premisas podemos afirmar que los contactos básicos se realizan siguiendo las líneas del diagrama adjunto (vid. fig. 2).

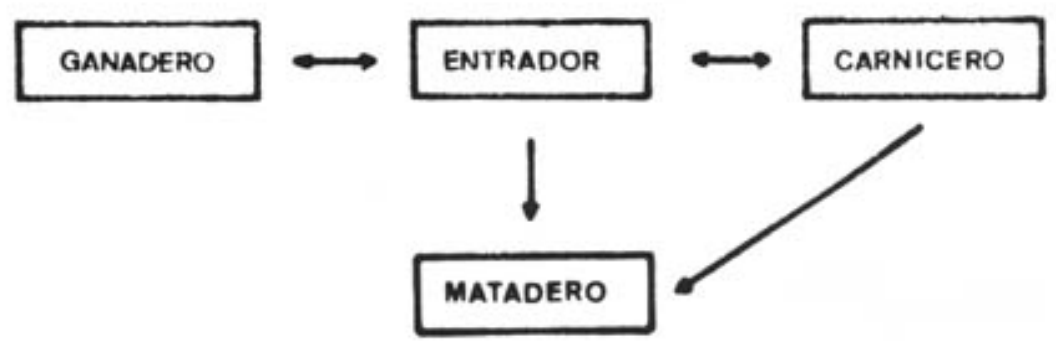

FIGURA 2- Relación e los usuarios con el matadero municipal de Alicante

El contacto más usual es aquel en que el "entrador" actúa como mayorista, es decir, compra las reses al ganadero o en ferias, las transporta con sus propios medios y las da a sacrificar al matadero. El carnicero paga unas tasas al Ayuntamiento por el servicio y la res al "entrador".

En ocasiones, algunos "entradores" alicantinos son comisionistas del ganadero, cobrando al carnicero la totalidad del animal; después deduce al precio de la canal los gastos de transporte y estabulación y se lleva la comisión prefijada con el ganadero. Evidentemente, lo más cómodo es actuar como mayorista.

Los actuales "entradores" del matadero alicantino (alrededor de una veintena) suelen sobrepasar los cincuenta años de edad, no están asociados bajo ninguna forma, su actividad se vincula a la actividad familiar y no hay perspectivas de continuación por lo que respecta a sus hijos. Al igual que en el resto del país, la ausencia de capital fijo es consustancial al tráfico comercial que desarrollan, por lo tanto las transacciones se realizan con volúmenes muy bajos de ganado (2). Tampoco practican una labor emprendedora de captación de nuevos clientes; 
la traducción de este detalle es que el matadero se encuentra con una oferta rígida que paraliza el volumen total de sacrificios. Todo ello, unido al auge de formas industriales de producción pecuaria (caso paradigmático del porcino), hace que el "entrador" participe de la languidez e inmovilismo del matadero público.

Tradicionalmente, los carniceros o minoristas han sido parte importante de los engranajes del matadero municipal, como se puede apreciar en el diagrama elaborado. A veces, el carnicero ha comprado las reses directamente en las granjas, pero casi en la totalidad de los casos compran a través de "entradores".

El minorista suele tener uno o dos "entradores", más o menos fijos, que le suministran una línea de carne ajustada a sus necesidades. La transacción se realiza en los corrales con el animal vivo. Después de sacrificar, limpiar, orear y refrigerar las reses, el Gremio Local de Carniceros y Charcuteros, que tiene la concesión del transporte en el matadero, lleva las canales hasta las mismas carnicerías. Las tarifas de matanza las abona el carnicero mediante unos recibos que el Ayuntamiento le envía mensualmente.

Es lógico pensar que las ya mencionadas mutaciones en el mercado de la carne, así como modificaciones en los propios carniceros, han hecho transformar los planteamientos y actividades de este colectivo. Antes, cuando la práctica totalidad de los minoristas compraban en el matadero municipal, recibían la res completa, despojos incluidos con los que elaboraba embutidos y otros productos. Sin embargo, con el paso del tiempo y el auge de los mataderos industriales privados, la situación ha cambiado bastante. El carnicero ha ido perdiendo profesionalidad, cada vez son menos los que saben sacrificar, embutir o despiezar. La mayoría sigue la tradición familiar sin ninguna especialización o montan un negocio de este tipo porque carecen de otras perspectivas, convirtiéndose así en meros expendedores de carne.

Los carniceros han dirigido sus miras a los mataderos industriales, de manera que aproximadamente el $80 \%$ de los minoristas alicantinos trabajan con ellos, y sólo van al matadero municipal en contadas ocasiones, contribuyendo de esta forma a su incuestionable crisis. Los modernos mataderos privados casi siempre cuentan con sala de despiece, detalle muy importante porque permite al carnicero soslayar el animal completo con sus despojos y pedir solamente aquellas piezas que tienen salida en el negocio en función de su clientela.

\section{Especies sacrificadas en el matadero municipal de Alicante}

El estudio de las especies que se sacrifican en el matadero público de Alicante también nos refleja los cambios más recientes que se han producido en el sector cárnico. El análisis del cuadro y gráficos adjuntos son fiel exponente de la realidad crítica que atraviesa el matadero municipal, el cual sacrifica vacuno, ovino, caprino, equino y porcino, viéndose perjudicado por el desvío del consumo hacia el porcino y pollo, especies con alto índice de conversión, cebadas intensivamente y de carne menos costosa. Los carniceros alicantinos se proveen normalmente de pollo y cerdo a través de mataderos industriales que no están radicados en nuestra provincia.

El cuadro I pone de manifiesto el número, peso en canal total y peso medio unitario de las especies sacrificadas entre 1983 y 1987. Aunque la serie es corta, resulta significativa para lo que pretendemos demostrar. Así, aparece de manera rotunda el descenso de sacrificios, 
Cuadro I

EVOLUCION DE LOS SACRIFICIOS DE DISTINTAS ESPECIES REALIZADOS EN EL MATADERO MUNICIPAL DE ALICANTE.

\begin{tabular}{|c|c|c|c|c|c|c|c|c|c|c|c|c|c|c|}
\hline \multirow[b]{3}{*}{ AÑos } & & & & & & & OS 1 & $33-8$ & & & & & & \\
\hline & \multicolumn{3}{|c|}{ VACUNO } & \multicolumn{3}{|c|}{ EQUINO } & \multicolumn{3}{|c|}{ OVINO-CAPRINO } & \multicolumn{3}{|c|}{ PORCINO } & \multicolumn{2}{|c|}{ TOTAL } \\
\hline & A & B & c & A & B & c & A & B & $\mathrm{c}$ & A & B & $\mathrm{c}$ & A & $\mathrm{c}$ \\
\hline 1983 & 7.595 & 230,75 & 1.752 .590 & 775 & 150,39 & 116.552 & 39.317 & 9,76 & 872.231 & 3.203 & 63,84 & 204.503 & 100.950 & 2.945 .945 \\
\hline 1984 & 6.595 & 235,63 & 1.554 .006 & 699 & 138,67 & 96.936 & 84.131 & 9,36 & 787.752 & 2.902 & 61,09 & 177.285 & 94.307 & 2.621 .779 \\
\hline 1985 & 5.432 & 250,17 & 1.358 .965 & 737 & 140,47 & 103.530 & 75.063 & 9.62 & 722.149 & 2.261 & 61,08 & 138.104 & 83.493 & 2.302 .641 \\
\hline 1986 & 4.482 & 247.53 & 1.1099 .434 & 768 & 137,62 & 105.700 & 66.955 & 9,46 & 633.981 & 1.508 & 53,92 & 81.319 & 73.720 & 1.932 .432 \\
\hline 1987 & 3.912 & 242,41 & 948.334 & 687 & 130,81 & 89.869 & 64.721 & 9,29 & 601.439 & 970 & 38,40 & 37.251 & 70.290 & 1.676 .893 \\
\hline
\end{tabular}

Fuente: Excmo. Ayuntamiento de Alicante. A, Número de cabezas sacrificadas; B, Peso medio unitario; C, Peso en canal total. 
salvo en el ganado equino que, por su especial idiosincrasia, sufre moderados altibajos. La reducción más acusada está en el porcino (pasa de 3.203 cabezas en 1983 a 970 en 1987); es la especie que más y mejor se aprovecha y por eso, los mataderos industriales, que elaboran productos derivados y despiezan las canales, prestan al carnicero mejor servicio que el matadero público. De ahí que el sacrificio municipal de porcino, según el coordinador de mataderos y mercados del Ayuntamiento de Alicante, tienda "matemáticamente a cero" (3). El vacuno, ovino y caprino también ven disminuir sus matanzas, debido a que el matadero municipal tiene que enfrentarse a una oferta poco maleable. Si los "entradores" no llevan reses, la matanza no crece. El aumento de la afluencia de animales es muy difícil porque los "entradores" no practican una política de captación de nuevos clientes. Los ganados más sacrificados son el ovino y el caprino, especies muy demandadas y consumidas tradicionalmente en Alicante.

También es importante mencionar la generalizada reducción del peso medio unitario, incluido el equino. Esto denota la adecuación progresiva a las normas de la CEE, que abogan por unas canales de menor peso, detalle especialmente significativo en el porcino. El vacuno, por su parte, aunque ofrece fluctuaciones, refleja un peso medio por cabeza mayor al final de la serie que en 1983, con el objeto de lograr canales que den mayor rentabilidad por tratarse de una carne costosa.

La reducción del volumen de matanza ya comentado se aprecia nítidamente en el total de kilogramos de carne en canal producida (vid. cuadro I). Se pasa de $2.945 .945 \mathrm{Kg}$. en 1983 a 1.676.893 Kg. en 1987; hay una pérdida del 43\% en tan sólo cinco años. Sería interesante conocer datos precisos sobre el consumo de carne en Alicante y sobre la red de abastecimiento, pero esto resulta imposible al no existir ningún organismo que ejerza dicho control. El comercio cárnico es libre y la carne foránea sólo tiene obligación de ser inspeccionada sanitariamente en el lugar de origen. Además, Alicante es una plaza compleja por la existencia de elementos distorsionadores como son los hipermercados de San Juan y de San Vicente del Raspeig; la carne tiene como destino dichos municipios pero los consumidores son alicantinos prácticamente en su totalidad. No obstante, los responsables del matadero municipal afirman, como indica el cuadro I, que su participación en el consumo cárnico del municipio alicantino es cada vez menor, estimándose que su aporte actual gira alrededor de tan sólo el $40 \%$ del total consumido. El resto procede de mataderos industriales privados situados fuera de la provincia, trazándose los principales vectores, aunque no existen datos, desde Valencia, Murcia, Barcelona, Burgos y Toledo, centros dotados de estructuras de sacrificio a gran escala.

Los gráficos siguientes resaltan otro de los problemas más acuciantes del matadero municipal: la acusada estacionalidad. Las matanzas concentradas en determinadas épocas del año responden a las demandas de los usuarios y a las disponibilidades de ganado. Las necesidades de la población genera una demanda dispersa, a veces caótica, con altibajos, y nada racional para el funcionamiento del matadero.

Las figuras 3 y 4 aluden al número de cabezas sacrificadas de vacuno y a su peso medio unitario respectivamente. Aunque en el volumen total de sacrificios de todas las especies existen tres picos: Semana Santa, y sobre todo verano y Navidad, en el ganado vacuno encontramos un nivel de matanzas mensuales bastante estable, si bien el incremento más notable se produce en verano debido a la demanda que supone una zona turística. El gasto invernal en carne de segunda clase queda equilibrado por las mejores piezas en el estío. Esto 


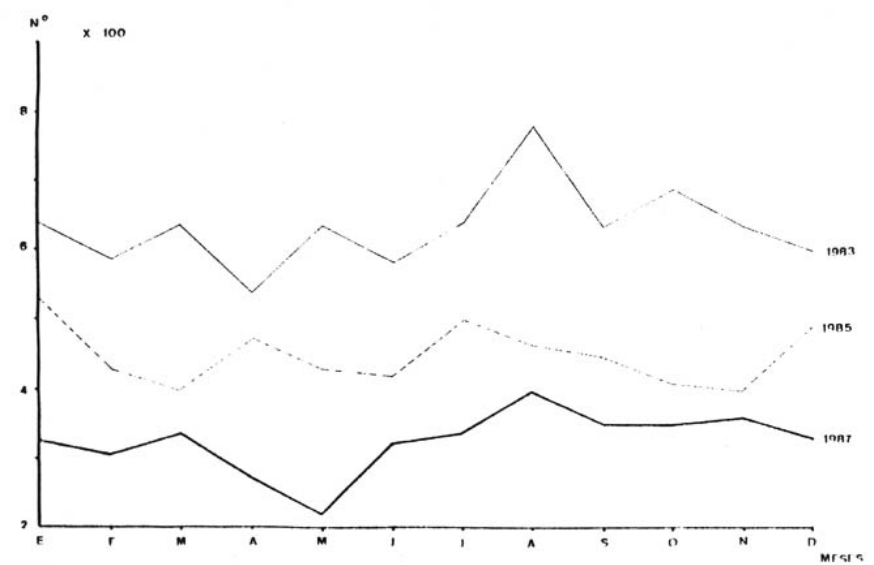

FIGURA 3- Número de cabezas de ganado vacuno sacrificadas mensualmente en el matadero municipal de Alicante. Años 1983, 1985 y 1987.

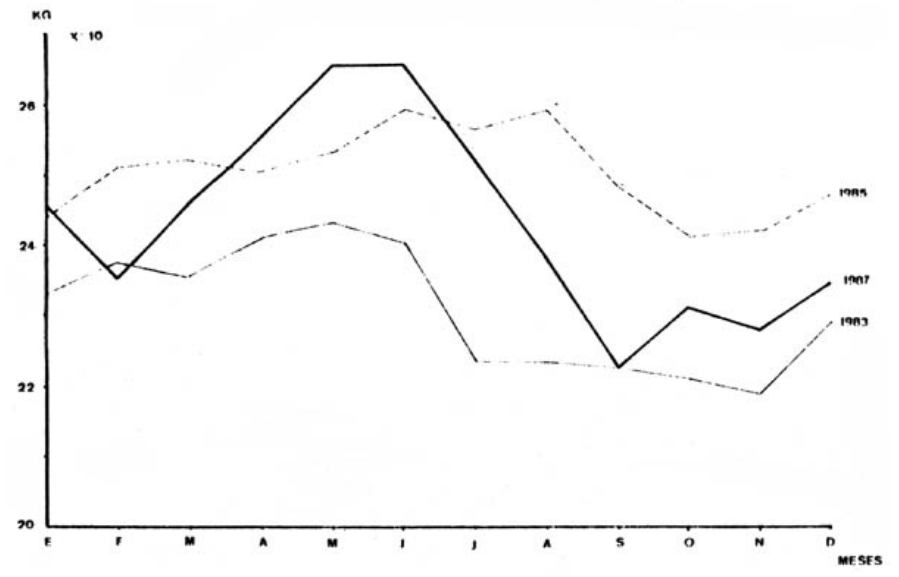

FIGURA 4- Peso medio unitario del ganado vacuno sacrificado mensualmente en el matadero municipal de Alicante. Años 1983, 1985 y 1987. 


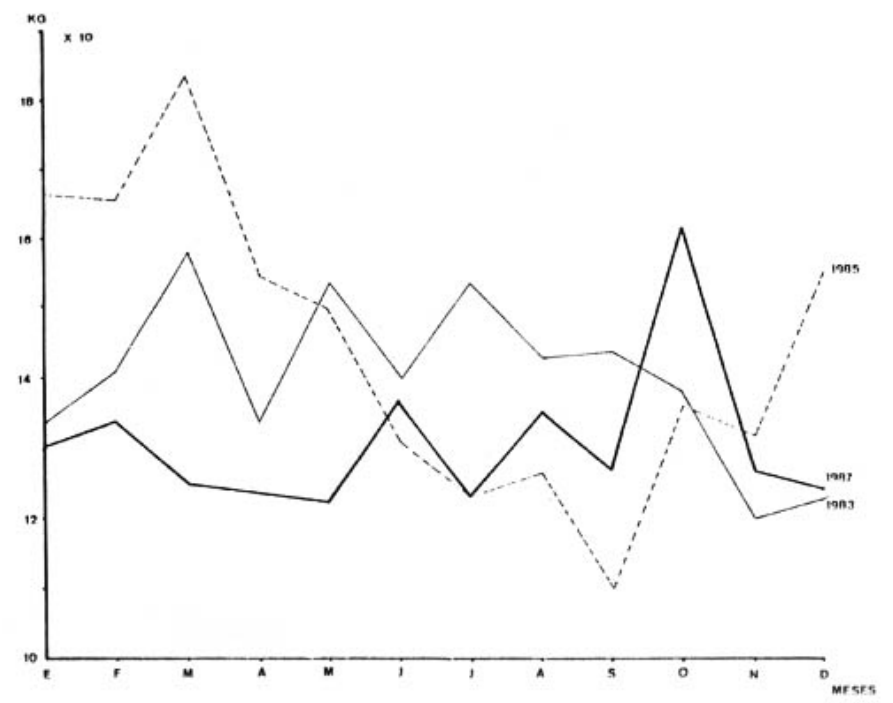

FIGURA 5- Número de cabezas de ganado equino sacrificadas mensualmente en el matadero municipal de Alicante. Años 1983, 1985 y 1987.

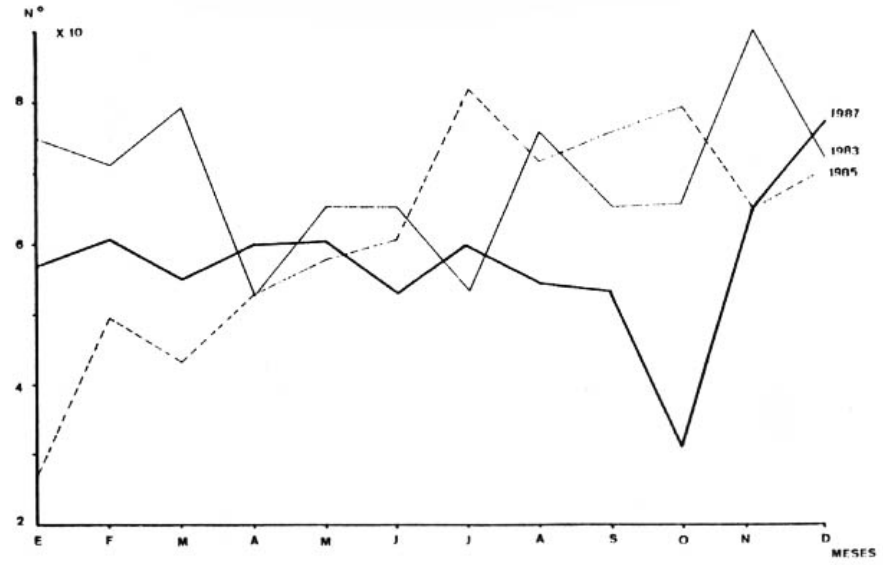

FIGURA 6- Peso medio unitario del ganado equino sacrificado mensualmente en el matadero municipal de Alicante. Años 1983, 1985 y 1987. 
se corrobora con la figura 3, donde se aprecia un ligero predominio de los animales más jóvenes desde comienzos del verano hasta finales del invierno, cuando el peso medio comienza de nuevo a incrementarse.

Las figuras 5 y 6 , referentes al sacrificio de equinos, denotan una oferta poco estable. En España no sucede como en otros países europeos (v.gr. Francia) y el ganado caballar no se cría para carne, por lo tanto no pueden existir aportaciones más o menos sistemáticas al matadero. Generalmente se trata de caballos de silla desechados, aunque esto no es sinónimo de animales ajados y/o enfermos, ya que el control sanitario es estricto. Los pesos medios unitarios mensuales reflejan también esa oferta inestable, tanto en cantidad como en edad y peso.

Por su parte, el ovino y el caprino (figs. 7 y 8), que se contabilizan juntos en las estadísticas de matanza del Ayuntamiento, tienen un volumen de sacrificio a lo largo del año bastante equilibrado, aunque no tan uniforme como en el caso del vacuno. Sin embargo, se vislumbra un incremento de matanza en Semana Santa, en verano y sobre todo en diciembre, en función de la demanda; gran parte de las enorme cifras navideñas se deben al sacrificio sistemático de cabritos, matiz que se aprecia mejor observando los pesos medios unitarios (fig. 8). El peso medio por cabeza sufre un incremento progresivo desde la primavera hasta conseguir los valores más importantes en el estío, momento a partir del cual el descenso es acelerado, para llegar al invierno con cifras reducidas. Esto se explica por los pesos medios de las canales de cordero (alrededor de 8-10 Kg.) y de cabrito (unos $4 \mathrm{Kg}$.) y también por la orientación productiva que tienen estas especies siguiendo las directrices del mercado.

Con el porcino (fig. 9 y 10) sucede prácticamente lo mismo que en el caso anterior. Es un nivel de matanza estable durante todo el año (pero tendente a la baja), aunque con un pico tímido en verano y otro rotundo en diciembre, lo que se consigue gracias a los numerosos lechones que solicitan las fechas. La figura 10 es reveladora del descenso que experimentan los pesos medios por cabeza al llegar el invierno, fundamentalmente en el año 1987, que logra alcanzar valores tan exiguos como esos 14'55 Kg/unidad. Las fluctuaciones de los pesos medios en 1987, sobre todo en la primera parte del año, se deben a factores coyunturales, fruto de los titubeos lógicos que preceden a la extinción de la línea de matanza de porcino en el matadero municipal. Se llevan al sacrificio cada vez menos partidas homogéneas de cerdos en peso y características; se tiende, como en el caso del equino, a matar animales cebados individualmente, esporádicos, cuando la economía del propietario lo requiere.

\section{Área de abastecimiento del matadero municipal}

El radio de acción de los "entradores", o zonas que abastecen de reses al matadero municipal de Alicante, se ha delimitado a través de encuesta a los mismos "entradores". Se puede afirmar con notable garantía que el matadero público alicantino se nutre principalmente del sur provincial y de provincias vecinas. Esto lo propician el ahorro de los costes de transporte por parte de los "entradores" y el hecho de que el animal se traslada vivo, evitándose así los largos recorridos.

El ganado vacuno procede del Bajo Segura y Elche en un 95\%; el resto es murciano. Las escasas reses porcinas que se sacrifican actualmente suelen ser de Alicante y Muchamiel. Las reses ovinas y caprinas tienen su origen en el área meridional alicantina (alrededor de un 


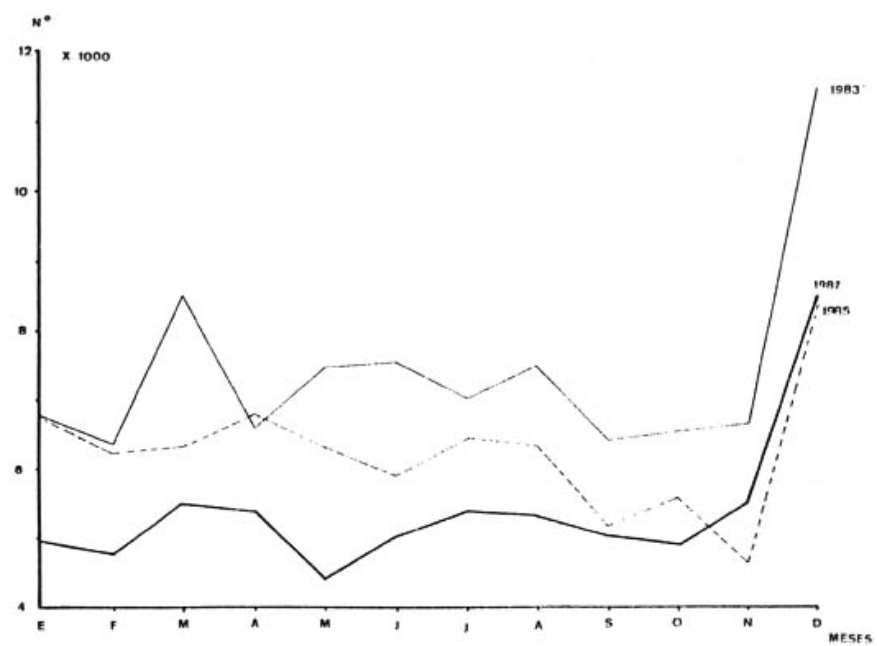

FIGURA 7- Número de cabezas de ganado ovino-caprino sacrificadas mensualmente en el matadero municipal de Alicante. Años 1983, 1985 y 1987.

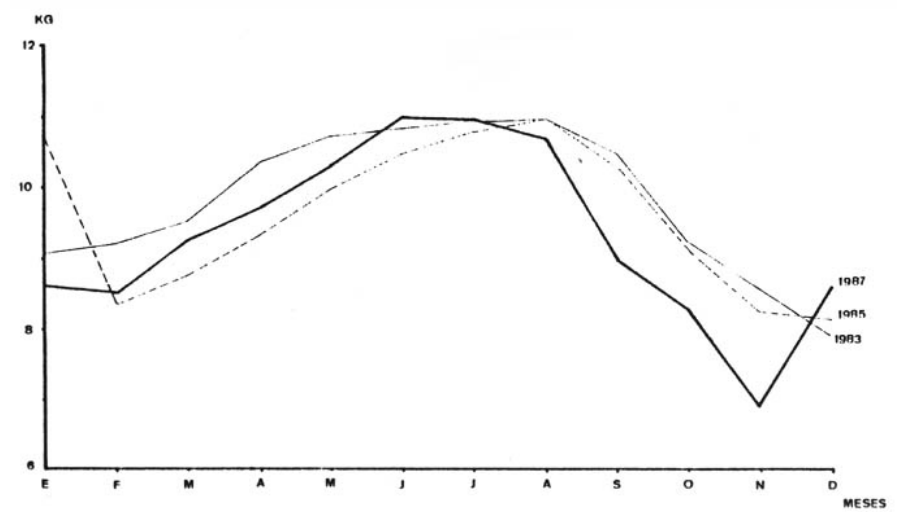

FIGURA 8- Peso medio unitario del ganado ovino-caprino sacrificado mensualmente en el matadero municipal de Alicante. Años 1983, 1985 y 1987. 


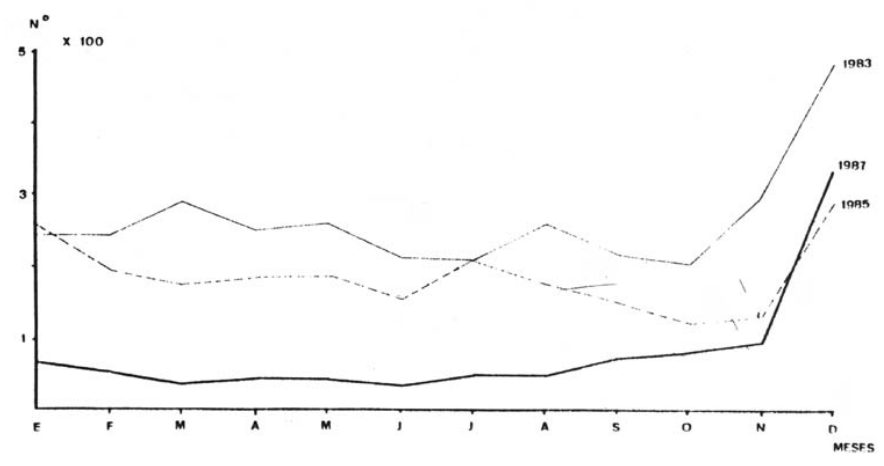

FIGURA 9- Número de cabezas de ganado porcino sacrificadas mensualmente en el matadero municipal de Alicante. Años 1983, 1985 y 1987.

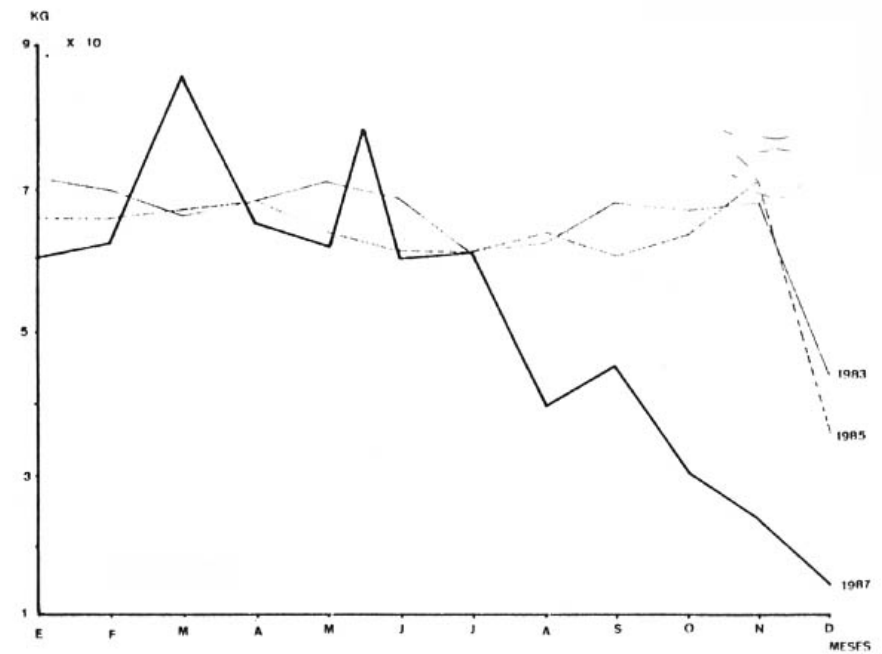

FIGURA 10- Peso medio unitario del ganado porcino sacrificado mensualmente en el matadero municipal de Alicante. Años 1983, 1985 y 1987. 
$50 \%$ ), Murcia (25\%) y Granada (15\%). El 10\% restante suele ser de Albacete o Almería. Los équidos llegan también desde el Bajo Segura-Elche (50\%), Murcia (30\%) y a veces Albacete y Granada.

Por su parte, el término municipal de Alicante no es un área significativamente pecuaria. Sus aportes actuales al matadero público son en general muy reducidos, suponiendo el $8 \%$ para el vacuno, el $6 \%$ para el ovino-caprino, el $38 \%$ del porcino y nulo en el caso del ganado equino. Estas apreciaciones indican claramente el carácter foráneo de las reses vivas que entran en el matadero municipal alicantino. El área alicantina es eminentemente consumidora y la tradicional disociación entre zonas de consumo, de producción de reses y productoras de carne aparece aquí muy clara.

\section{Principales problemas que exhibe el matadero municipal}

El matadero municipal de Alicante, como casi todos los mataderos públicos, presenta una serie de problemas que dificultan su óptimo funcionamiento. Algunos de estos problemas son inherentes a su propio carácter público, mientras otros proceden de los cambios que ha experimentado el sector cárnico en las últimas décadas.

Los problemas más importantes que presenta el matadero municipal alicantino son los siguientes:

1.- Los aumentos demográficos, de renta per cápita y de población urbana conllevan un mayor consumo de proteínas nobles, descollando sobremanera la demanda de pollo y cerdo, especies cebadas intensivamente. Este cambio perjudica al matadero municipal porque sus mayores volúmenes de matanza corresponden al ganado vacuno, ovino y caprino, cuyo engorde intensivo aún no se ha generalizado, casi no tienen tratamiento industrial y resultan carnes de elevado precio.

Además, el cuadro II denota el incremento progresivo tanto de población como de renta familiar disponible en el municipio de Alicante. El aumento de estas dos variables siempre ha conllevado un mayor consumo de carne, aunque quizás en el futuro la tendencia sea distinta debido a la influencia reciente de diversas modas alimenticias. Como ya hemos indicado, no es fácil dilucidar qué valor alcanza el consumo cárnico total en el municipio, pero conociendo la imparable y evidente retracción que sufren las matanzas en el matadero público, se puede comprender el enorme papel que en muy poco tiempo han conseguido desempeñar los mataderos industriales foráneos por lo que se refiere a la provisión de carne a Alicante.

2.- Como ya se ha planteado, los minoristas han modificado sus hábitos. Antes adquirían animales enteros para elaborar embutidos y otros derivados, pero ahora prefieren recurrir a los mataderos industriales, que les sirven las piezas que desean según tengan una clientela más o menos selecta. El matadero municipal no tiene sala de despiece ni elabora productos con el llamado "quinto cuarto" (despojos), por lo tanto su oferta es muy limitada para los usuarios.

Estos dos factores exógenos, mutaciones en los hábitos de los carniceros y transformaciones en el consumo de la población, hacen disminuir progresivamente las matanzas en el matadero municipal. Esto deriva a su infrautilización, siendo su capacidad teórica 
Cuadro II

\begin{tabular}{|c|c|c|c|c|}
\hline & 1970 & 1981 & 1983 & 1985 \\
\hline $\begin{array}{l}\text { POBLACIÓN } \\
\text { DE HECHO }\end{array}$ & 181.550 & 245.962 & 251.162 & 255.608 \\
\hline $\begin{array}{l}\text { RENTA FAM. } \\
\text { DISPONIBLE } \\
\text { (pesetas) }\end{array}$ & - & 442.620 & 533.950 & 670.216 \\
\hline
\end{tabular}

Fuente: Caja de Ahorros de Alicante y Murcia, Datos y Series Estadísticas.

mucho más alta que la real. En 1987 se sacrifican $1.676 .893 \mathrm{Kg}$., pero teóricamente, a pleno rendimiento, se podrían conseguir alrededor de 5.000.000 Kg., es decir, tres veces más. La capacidad teórica podría incrementarse si se hiciesen turnos de trabajo similares a los que practican empresas privadas como Fuertes, S.A. (El Pozo).

3.- Es sabido que el matadero municipal tiene como objetivo principal el abastecimiento de carne a la población con las suficientes garantías higiénico-sanitarias. No se trata de un matadero especializado, sino que debe prestar servicio a los usuarios que lo requieran. Por eso, como todo servicio público, no tiene ánimo de lucro y su rentabilidad se revela casi imposible. Incluso, las tarifas de sacrificio y faenado, pernoctación de reses en los corrales, incineración de animales, conservación de refrigerados o entrada y permanencia de camiones, son tan bajas que impiden la autosuficiencia del matadero. Esta instalación municipal genera actualmente un déficit anual de unos 50 millones de pesetas.

4.- A las apreciaciones del punto anterior se une la ausencia de una gestión profesionalizada con criterios empresariales para agudizar la falta de rentabilidad y las pérdidas que supone al erario público. Al ser una empresa de servicio público, su funcionamiento depende del uso que hagan "entradores" y carniceros, a menudo con ofertas y demandas poco elásticas.

También en esto aparecen los mataderos industriales como competidores eficaces, siguen directrices rentables en todos sus movimientos. Su gestión se encamina hacia una política comercial eficaz (agentes de ventas, marketing, publicidad), un volumen de matanza considerable, unas inversiones constantes y una pretensión de generar las economías de escala necesarias. Un caso paradigmático digno de mención es el de Fuertes, S.A. (El Pozo). Este matadero industrial vinculado únicamente al porcino, con 600 empleados y $5.000 \mathrm{CV}$ de potencia instalada, sacrifica 500.000 reses al año (2.000 diarias), lo que a una media de $70 \mathrm{Kg}$. la canal supone aproximadamente 35 millones de kilogramos, trabajando en temporada alta sólo al 65\% de su capacidad. Además, posee 26 delegaciones repartidas por toda España más la central de Alhama de Murcia.

5.- Otro aspecto problemático es el concerniente a la mano de obra. En el matadero municipal la plantilla está en función de la matanza y no la matanza en función de la plantilla, de ahí que de forma pareja a la reducción del número de sacrificios se produzca la del personal laboral. A comienzos de los años ochenta el matadero disponía de cuarenta y cinco 
trabajadores, pero actualmente sólo son treinta y uno y con perspectivas de una mayor retracción. La necesidad de reducir la plantilla no es porque la robotización y la tecnología así lo exijan, sino porque la acentuada estacionalidad de los sacrificios redunda en unas jornadas laborales muy irracionales, que dependen de las reses que entren. Esto no sucede en los mataderos industriales, donde la diversidad de actividades hace que el matarife pueda realizar, si escasea la matanza, otras laborales (v.gr. despiezar, embutir o tratar despojos) hasta cubrir su jornada de trabajo. Esto repercute en la rentabilidad de la empresa; los empleados trabajan a pleno rendimiento, cosa que no ocurre en este servicio público.

Otras veces sucede lo contrario, es decir, en épocas de mucho trabajo (verano y Navidad), por la gran afluencia de reses, se hace imprescindible trabajar más horas de las estipuladas, pero esta urgencia se cubrirían antes con empleados de empresas privadas que con funcionarios públicos.

6.- Otro problema fundamental con el que tropieza el matadero municipal es el de la tecnología y modernización de instalaciones. El Ayuntamiento de Alicante ha hecho un verdadero esfuerzo económico para dotar al matadero de los más modernos adelantos. Desde 1984-85 se han realizado inversiones por valor de 100 millones de pesetas para adecuar las instalaciones a la legislación técnico-sanitaria, pero esta cifra, que procede de los contribuyentes, resulta ridícula si la comparamos con las constantes reinversiones que practican los mataderos industriales.

A pesar del interés mostrado por los poderes públicos para dotar al matadero, sobre todo ante los imperativos del Plan General Indicativo de Mataderos, el camino recorrido ha sido arduo y lento. Hasta hace muy pocos años, y a veces en la presente década, los métodos empleados eran totalmente artesanales y carentes de las más elementales condiciones. No obstante, todavía se alzan críticas que reivindican mejores condiciones de trabajo para el personal laboral, un sistema de eliminación de residuos y olores y un buen funcionamiento de las cámaras frigoríficas (4).

Como corolario, la existencia irrefutable de estos problemas que encuentra el matadero municipal ha hecho reflexionar al Ayuntamiento sobre el futuro del mismo. Han llegado a la conclusión de que debido a las actuales y especiales características del mercado cárnico, el matadero se erige como una industria privada por excelencia. Por lo tanto, habría que dotarlo de una imagen lo más parecida posible a una empresa privada para que fuera competitivo, rentable y eficaz. El sendero elegido es el de la concesión administrativa, es decir, se contempla el encauzamiento hacia algún tipo de gestión indirecta, a través de personal laboral. El Ayuntamiento sólo se encargaría ya de aprobar el reglamento y las tarifas por los que la empresa que tuviera la concesión regiría las instalaciones, controlar el abastecimiento de carne en óptimas condiciones sanitarias, supervisar su funcionamiento. Son muchas las voces que se levantan para exponer la necesidad que tienen los mataderos públicos de cambiar de gestión o de asociarse. La alternativa es diáfana: o modifican sus planteamientos o desaparecen (5).

El Ayuntamiento pretende una concesión integral y no parcelada como hasta ahora. La concesión del transporte de la carne la tiene el Gremio Local de Carniceros y Charcuteros desde 1980 por diez años. Por otro lado, en 1981 y por un período de siete años se dio la concesión del tratamiento de los despojos a una empresa privada. Esto último es sumamente ilógico porque esta empresa participa de los mismos problemas laborales que origina la irregularidad de sacrificio del matadero. Por eso se pretende que la concesión sea integral. 
Actualmente se prevee una futura concesión con el Gremio Local de Carniceros y Charcuteros; de ahí el interés del Ayuntamiento por modernizar las instalaciones y conseguir un adecuado nivel técnico, sobre todo desde que el Plan General Indicativo de Mataderos le ha asignado un nuevo papel comarcal (6), es decir, el matadero municipal de Alicante ejercerá su influencia sobre el área metropolitana: Alicante, Campello, Muchamiel, San Juan y San Vicente del Raspeig, atendiendo a una demanda potencial de 311.000 habitantes en 1985. Si la concesión fuese un hecho supondría una labor denodada de cambio y transformación, no demasiado en instalaciones pero sí en gestión.

El "nuevo" matadero podría ser más competitivo con los industriales porque ampliaría su campo de acción y realizaría labores que el Ayuntamiento ahora no puede llevar a cabo, como compra de reses, dotación de sala de despiece, marketing, mejor servicio de transporte, planificación de precios. Además, la mano de obra podría estar plenamente utilizada, aprovechando la legislación laboral en cuanto a contratos de trabajo, horarios y salarios.

Por todo ello, el Ayuntamiento y sus técnicos son totalmente conscientes de que un matadero es una industria de funcionamiento y talante privados en las actuales condiciones de economía, mercado y demanda. De esta forma, el matadero municipal se colocaría al mismo nivel que tienen los servicios que prestan los mataderos industriales.

\section{NOTAS BIBLIOGRÁFICAS}

1 GRAFE, Fernando, JIMÉNEZ, Rafael, "La crisis del mercado tradicional de la carne: una visión de futuro", El Campo, 94, abr-jun. 1984, p. 56.

2 GRAFE, Fernando, JIMÉNEZ, Rafael, Ibid, p. 58.

3 Nuestro más sincero agradecimiento por la ayuda prestada al coordinador de mercados y mataderos del Excmo. Ayuntamiento de Alicante, D. Diego Agulló, al veterinario y al administrador del matadero municipal de Alicante, D. César Corredor y D. Juan Alfonso respectivamente, y al carnicero minorista D. Fernando Vivas.

$4 \quad$ Diario Información, Alicante, martes 27 de septiembre de 1988.

5 ASSESSORIA COMARCAL DE L'HORTA SUD, “O se mancomunan o desaparecen”, Generalitat, primera quincena, febrero 1983, pp. 19-20.

6 GUITIAN LÓPEZ-CARO, Juan José, "El Plan General Indicativo de Mataderos: su génesis y desarrollo", Estudios Agro-Sociales, 128, julio-septiembre 1984, pp. 127-134. 